\title{
Developmental Determinants at the Mammalian Optic Chiasm
}

\author{
R. W. Guillery, ${ }^{1}$ C. A. Mason, ${ }^{2}$ and J. S. H. Taylor ${ }^{1}$ \\ 'Department of Human Anatomy, University of Oxford, Oxford OX1 3QX, United Kingdom and 'Departments of \\ Pathology, Anatomy, and Cell Biology, Centre for Neurobiology and Behaviour, College of Physicians and \\ Surgeons, Columbia University, New York 10032
}

The optic chiasm is the point at the ventral midline of the diencephalon where the nerve fibers from the two eyes meet. Classically, it has been known as the place where groups of retinal axons segregate to pass into the optic tract on either the same or the opposite side of the brain (Figs. 1,2). This segregation is dependent upon the retinal position of the ganglion cells from which the axons arise: axons from the nasal retina all cross to the opposite side, whereas many from the temporal or ventrotemporal part of the retina (temporal crescent) remain uncrossed. This segregation of the axons into a crossed and uncrossed component allows the appropriate bilateral connections that underlie normal binocular vision to form.

The optic chiasm may seem to be one of the simpler choice points for growing axons in the CNS, involving merely a guidance of axons from the temporal retina into an uncrossed path and from the nasal retina into a crossed one (Figs. 1, 2). The developmental problem is to understand how the partial crossing is produced when the nerve fibers first grow towards the brain. If the molecular signals producing this segregation at the chiasm could be defined, then an understanding of how the partial segregation develops in this and in other systems might result. However, the apparently simple arrangement of axons shown in Figure 1 leaves out the complexities that characterize this phylogenetically old pathway, which probably developed a great variety of specializations during its evolutionary history.

Although there have been several studies of axonal guidance across the midline in vertebrate (Dodd et al., 1988; Yagimuna et al., 1991; Bernhardt, 1994; Shepherd and Taylor, 1995) and invertebrate development (Klämbt et al., 1991; Seeger et al., 1992), the optic chiasm can be seen as an unusually promising part of the vertebrate CNS for studying how the development of well-defined, complex neural pathways may be controlled. There is now a wealth of information available about the spatial and temporal relationships of retinofugal axons as they travel through the region of the optic chiasm towards their topographically organized termination sites. Information is available about different developmental patterns in different species and a num-

\footnotetext{
Received Aug. 1, 1994; revised Feb. 1, 1995; accepted Feb. 15, 1995.

We thank Riva Marcus and Gary Baker for their comments on the manuscript, and Brian Archer and Colin Beasley for their help with photography This work was supported by grants from the Wellcome Trust to both R.W.G and J.S.H.T., and by the NIH to C.A.M.

Correspondence should be addressed to Prof. R. W. Guillery, Department of Human Anatomy, University of Oxford, South Parks Road, Oxford, OX1 3QX, United Kingdom.

Copyright (C) 1995 Society for Neuroscience $0270-6474 / 95 / 154727-11 \$ 05.00 / 0$
}

ber of mutants are known that show well-defined abnormalities of the optic chiasm. The chiasm can no longer be regarded simply as the region where some axons cross their partners from the other eye, and others diverge into an uncrossed course. There is now an opportunity to look more closely at the cellular and molecular events producing the characteristic and rigidly choreographed patterns of axonal growth. The development of the optic chiasm and the reorganization of retinotopic order that occurs within region of the chiasm can now be seen in terms of a number of discrete steps, each probably relatively simple in itself, which together produce the final developmental sequence. Further, the region of the chiasm is responsible not merely for a segregation of crossed from uncrossed axons but also for the guidance of early axons that allows orderly maps of the retina to be transferred to the appropriate end-stations in the brain.

The organization of the optic chiasm can be studied with relative ease in the adult and recently, with newer methods, it has also become possible to study it at all developmental stages when growing axons are entering these distinct pathways. It is now possible to make direct observations of the living axons as they are deflected from one course and enter another. Current experimental methods for studying fixed and living prenatal brains have provided new insights, clarifying many details of chiasmatic development, and demonstrating some of the basic rules followed by the relevant developmental processes (for reviews, see Guillery, 1992; Reese and Baker, 1992; Godement and Mason, 1993; Sretavan, 1993).

The rules that govern how axons are assigned to a particular pathway vary with developmental stage and species. The course that an axon takes depends upon both retinal and chiasmatic factors. It is critically dependent upon the glial environment and on other axons within the optic chiasm. The nature of this dependence shows some striking differences hetween marsupials and eutherians and can be modified by experimental interference or some well-defined mutations, of which the albino is the best known.

In this article we stress the importance of understanding the developmental forces that produce the optic chiasm, but note also that the formation of the chiasm itself is at the base of the development of the whole visual system, providing important clues to understanding patterns of organization in thalamic, midbrain, and cortical centers. Each central relay must receive an appropriately mapped projection from the retina, and the pathway taken at the chiasm is an essential first step in producing these topographically precise projections. Although this article 


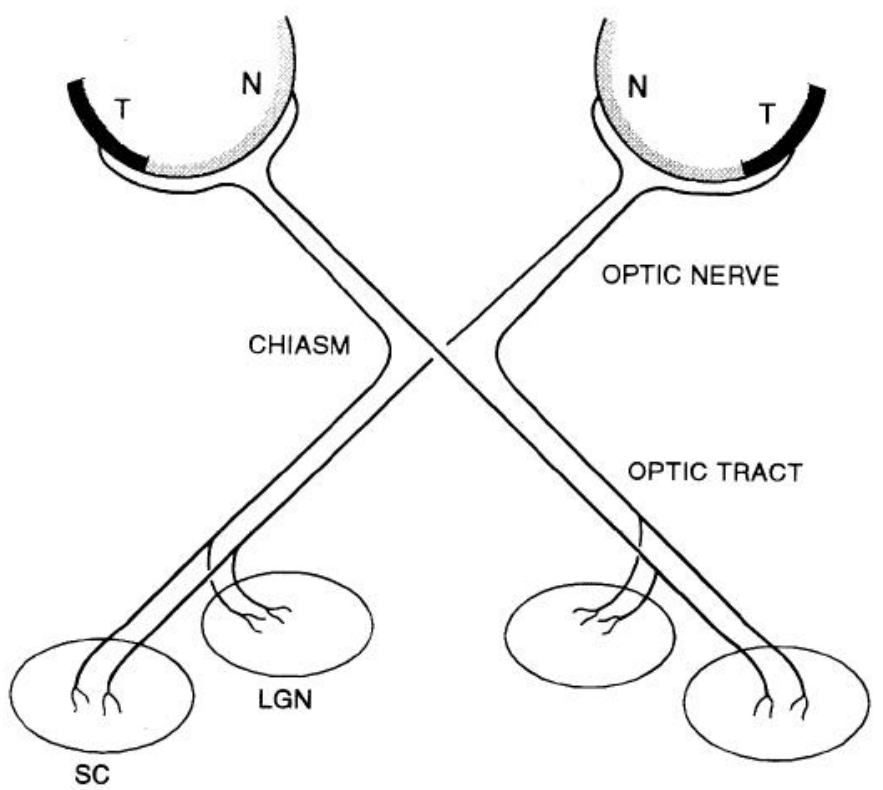

Figure 1. Diagram showing the position and pattern of decussation of retinal ganglion cell axons at the optic chiasm and their termination in the central visual relays of the lateral geniculate nucleus $(L G N)$ and superior colliculus $(S C)$. Axons from the temporal part of the retina $(T)$ remain uncrossed at the optic chiasm, while those of the nasal retina $(N)$ cross.

is mainly concerned with the mammalian optic chiasm, we include some reference to other vertebrates where these illustrate general points.

\section{The Retinal Ganglion Cells}

These are the nerve cells that give rise to the retinofugal axons with which we are here concerned. From the point of view of this article, retinal ganglion cells can be categorized in four ways: (1) when they were generated; (2) where their cell bodies lie in the retina; (3) whether their axons do or do not cross at the chiasm; and (4) to which morphological or functional cell class they belong. It has recently become clear that these four categorizations are closely related to one another.

In mammalian development, the earliest ganglion cells to be generated lie in the part of the retina above the future optic disk (the dorso-central retina; Fig. 3), and for these cells the chiasmatic course of the axon is independent of their retinal position (mice: Godement et al., 1987; Colello and Guillery, 1990; rats: Chan et al., 1993; ferrets: Reese et al., 1992; macaque monkey: Lia, 1992; short gray-tailed opossum: Taylor and Guillery, 1994). These early ganglion cells in the dorso-central retina that have uncrossed axons lie scattered among other cells having crossed axons, and it appears as though the pathway taken by these earliest axons at the chiasm is not directed by any specific mechanism. Rather, axons that happen to lie nearer to the lateral part of the optic nerve when they approach the chiasm have a greater tendency to stay on the same side (Godement et al., 1990; Marcus and Mason, 1993; Sretavan and Reichardt, 1993; Sretavan et al., 1994; and see Fig. 7A,E,F of Sretavan, 1990). Whereas later uncrossed axons in mice and ferrets approach the midline before turning (see below), these early axons turn straight from the lateral part of the optic nerve into the ipsilateral optic tract (Baker and Collelo, 1994).

The axons of this earliest-born cohort of ganglion cells either

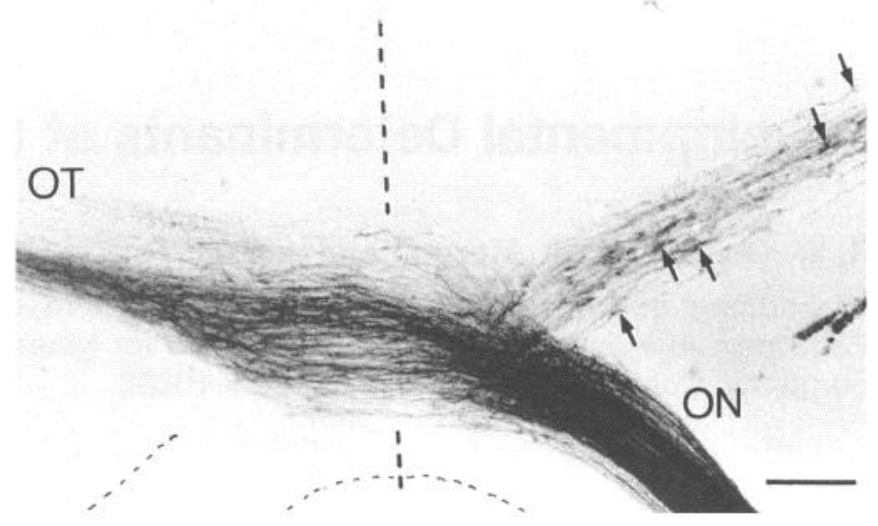

Figure 2. A horizontal section through the optic chiasm from an E16.5 rat in which the retinal ganglion cell axons in the optic nerve $(O N)$ to the right of the figure have been labeled with DiI and photo-oxidized. The nondecussating axons tipped with growth cones (arrows), turn lateral to the midline (dashed line), while decussating axons cross to the contralateral optic tract $(O T)$. From Taylor and Guillery (1994). Scale bar, $100 \mu \mathrm{m}$.
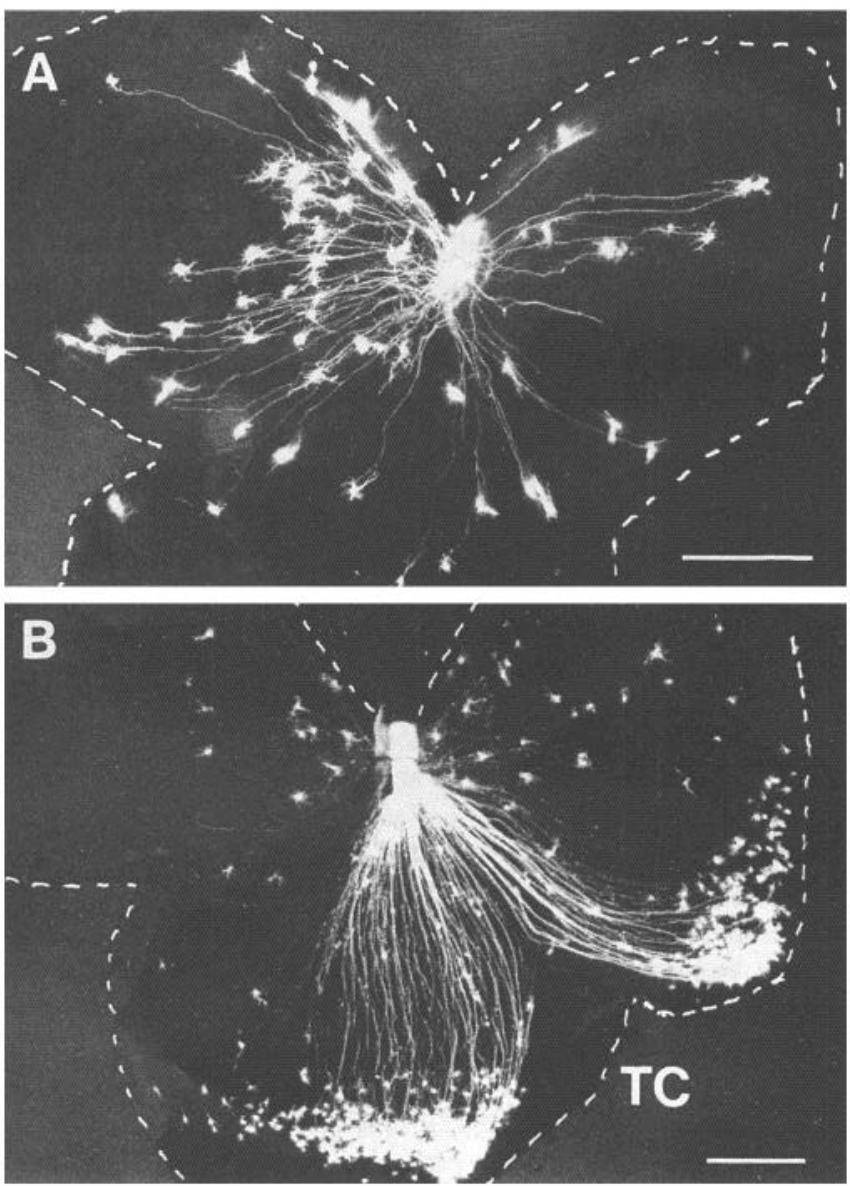

Figure 3. Two mouse retinas, $(A)$ at E15.5 and $(B)$ at E17.5, ipsilateral to a whole tract filled with $\mathrm{DiI}$ to show the ganglion cells that give rise to $(A)$ the early (dorso-central) uncrossed component and $(B)$ the later uncrossed component from the temporal crescent (TC). Scale bars, 300 $\mu \mathrm{m}$. 
lack the specific properties that cause later axons of nasal cells to cross and of temporal cells to remain uncrossed or, though specified within the retina, do not yet encounter the relevant chiasmatic cues. These early uncrossed cells probably do not survive in the adult (Thompson and Morgan, 1993), so that we know nothing about their functional or morphological class.

The next-horn cohort of retinal ganglion cells (which, in a cat, would be the beta or X-cells; Walsh et al., 1983) shows a clear naso-temporal division (Stone and Fukuda, 1974), with all adult nasal cells having crossed and all adult temporal cells having uncrossed axons. This naso-temporal dividing line appears quite suddenly in the experiments currently available for demonstrating it, which depend on the axons having entered the tract ( $\mathrm{Co}$ lello and Guillery, 1990; Godement et al., 1990; Baker and Reese, 1993). An important step in arguing that the retinal ganglion cells are specified with respect to the course that they take at the optic chiasm is that even at the early stages, the growing crossed and uncrossed axons are mingled with one another before they reach the optic chiasm (Baker and Colello, 1994). That is, the chiasmatic segregation of this later cohort of axons, in contrast to the early dorso-central cohort, must depend upon a property that is specifically related to retinal position. One can expect to obtain the clearest view of the developmental processes producing the chiasmatic segregation into crossed and uncrossed components from the axons reaching the chiasm at this second stage (E15-17 in mouse, E16-18 in rat, and E2832 in ferret).

During yet later developmental stages in many species there is a gradual increase in the number of axons from the temporal retina that cross at the chiasm (Walsh et al., 1983; Reese et al., 1992a). Details vary according to species. For instance, ferrets differ quite markedly from cats, in that the axons of the largest, late-born alpha cells are all crossed (Vitek et al., 1985; Reese and Baker 1990). In primates there are no crossed axons from the temporal retina at any stage (Stone et al., 1973; Chalupa and Lia, 1991). However, for nonprimate species there appears to be a general pattern of a well-defined line of decussation forming early and, as more axons arrive later, more and more taking a crossed course, as though either the retinal specification of temporal, or the chiasmatic cues that direct axons into the uncrossed pathway weaken as development proceeds.

\section{The Organization of Retinal Axons within the Optic Nerve}

Although there have been several descriptions of retinotopic order of axons throughout the adult mammalian optic nerve, chiasm, and tract (Polyak, 1957), the evidence was always controversial, and recent observations cast serious doubt on such order. There is now strong evidence that although the axons leave the eye with a rough retinotopic order, they disperse as they pass along the optic nerve, so that all or most of the order is lost when they enter the chiasm. The clearest evidence against an ordered arrangement in the optic nerve came from Horton et al. (1979), who labeled eight closely adjacent ganglion cells in the retina by injecting horseradish peroxidase (HRP) into the adult cat's lateral geniculate nucleus and then showed that of these eight axons, each took a different, independent course through the optic nerve. Axonal tracing studies in cat, ferret, and monkey have also shown the loss of retinotopic order as the axons were traced from the eye to the chiasm (Naito, 1986, 1989; Reese and Baker, 1993), and it is clear that in the adult rodent the crossed and the uncrossed components do not occupy different parts of the optic nerve near the chiasm (Baker and Jeffery, 1989), as would be expected from a retinotopically organized pathway.

The loss of retinotopic order seen along the adult nerve also characterizes the earliest developmental stages. Silver (1984) showed that axon bundles fuse on the way to the chiasm, and Williams et al. (1986) found individual axons switched from one hundle to another. The axons from the temporal crescent show a clear loss of topographic order when traced through the nerve and, as noted above, the axons that are destined to cross are mingled with those that will stay uncrossed (Colello and Guillery, 1990; Baker and Colello, 1994; Chan and Guillery, 1994). The position of an axon in the mid-portion of the optic nerve cannot be related directly either to its retinal origin or to its chiasmatic pathway, demonstrating that the course of the axons through the chiasm and into their terminal fields cannot be determined by their position in the nerve.

\section{Age-related Organization within the Optic Tract}

Although the axons lose their retinotopic order as they approach the chiasm, they gain a new order in the optic chiasm and tract. In many vertebrate species the axons in the optic tract are ar ranged in a deep to superficial order, with the earliest formed axons being deepest and the last most superficial, next to the subpial glia (frog: Gaze and Grant, 1978; fish: Easter et al., 1981; ferret: Walsh and Guillery, 1985; mouse: Colello and Guillery, 1992). Early in development, evidence for this agerelated order is seen in the distribution of the advancing growth cones. Within the extracranial part of the optic nerve, growth cones are distributed more or less evenly through the cross-sectional area of the nerve (Williams et al., 1986; Colello and Cuillery, 1992). Intracranially, in the juxta-chiasmatic nerve and in the tract, growth cones lie predominantly next to the sub-pial glia (Guillery and Walsh, 1987; Colello and Guillery, 1992; Reese et al., 1994). That is, the advancing growth cones tend to move towards the pia as they approach the chiasm and tract.

In fish and frogs the visual system develops while it is used. This means that new axons must be added to an already functioning system without disruption of vision. Within the retina, new cells are added at the periphery so that the radial dimension of the retina corresponds to ganglion cell age (Straznicky and Gaze, 1971; Johns, 1977). This is in contrast to the mammalian retina, which shows a less rigid central-peripheral pattern of cell genesis and therefore a weak correlation between the age of a cell and its retinal position (Sidman, 1961; Dräger, 1981; Walsh et al., 1983). Consequently, chronotopic order corresponds to radial topography in fish and frogs, but not in mammals. Axons in the optic pathways of frogs and fish show a more precise topographic organization than is found in mammalian visual systems (compare Scholes, 1979; Easter et al., 1981; Taylor, 1987, with Torrealba et al., 1982). However, there is some loss of order in the optic nerve, and a significant fiber reorganization also occurs at the optic chiasm of fish and frogs. Here the nature of the glial environment changes (Maggs and Scholes, 1986; Wilson et al., 1988; Levine, 1989), apparently producing an agerelated order within the optic tracts that is maintained to the visual relays (Scholes, 1979; Bernhardt and Easter, 1986; Taylor, 1987).

In mammals, the relative change in the position of the growth cones that produces the prechiasmatic age-related order also occurs at a point where the glial environment changes. Within the early optic nerve of ferrets and mice the glia are interfascicular, with cell bodies in the core of the nerve, and glial processes 
wrapping around individual bundles of axons. There is an abrupt border between this form of glia and the radial glia of the diencephalon (Silver, 1984; Guillery and Walsh, 1987; Colello and Guillery, 1992; Reese et al., 1994). Within the diencephalon, the original structure of the optic stalk is a tube lined by neuroepithelium and continuous with the third ventricle. This is still readily recognizable when the first axon bundles reach the chiasm. All of the glial cell bodies lie next to the ventricular cavity that still extends into the cranial end of the optic stalk, and slender, radial processes pass from these cell bodies to the subpial end-feet. It appears that when the growth cones pass from the interfascicular to the radial glia, the individual growth cones move towards the pial surface, generating a series of time-ordered layers of retinal axons.

This change in the arrangement of axons starts to occur as they leave the interfascicular glia. We do not know how rapidly the change occurs, or whether all axons follow the same pattern of growth, but there is a significant segregation of growth cones towards the pial surface before the axons encounter any of the growing axons from the other eye. That is, the change in order is a prechiasmatic change and it brings the axons to their chiasmatic interaction as two sets of sheets approaching each other close to the pial surface. Since the growth cones are near the pial surface prechiasmatically and also in the optic tract, we assume that their chiasmatic pathway is determined primarily as they lie close to the pial end-feet.

\section{Retinotopic Organization in the Optic Tracts}

In addition to the agc-related order, which provides a representation of retinal radial order in the tract of frogs and fish, there is also a representation of circumferential order in the tract. Axons from each of the four retinal quadrants have a specific distribution in the optic tracts (Scalia and Fite, 1974; Fujisawa et al., 1981; Fawcett and Gaze, 1982; Bernhardt and Easter, 1986). This organization is established as the axons pass through the optic chiasm (Scholes, 1979; Reh et al., 1983; Fawcett et al., 1984; Taylor, 1987). Axons from ventral and dorsal retina occupy, respectively, the anterior and posterior aspects of the optic tracts. Axons from nasal retina are dispersed across the width of the tract, and overlap the distribution of the temporal axons that gather in the middle of the tract. The position of the axons in the optic tract appears to lead them to the retinotopically appropriate region of termination in the optic tectum. Several studies have addressed how axons are guided to the appropriate parts of the visual pathways and terminal stations in nonmammalian species (see, e.g., Gaze, 1970; Udin and Fawcett, 1988).

In mammals, the crossed (nasal) and the uncrossed (temporal) axons generally overlap within the optic tract (Torrealba et al., 1982; Cucchiaro and Guillery, 1984; Chan and Guillery, 1994), although the nasal axons always outnumber the temporal axons and occupy a greater portion of the tract. In contrast, dorsal and ventral retinal axons segregate into the anterior and posterior aspects of the tract, respectively (Torrealba et al., 1982; Simon and O'Leary, 1992a; Reese and Baker, 1993; Chan and Guillery, 1994). This segregation arises within the optic chiasm, and is maintained throughout the optic tracts to the visual relays. It is possible that this segregation may govern the establishment of retinotopically ordered connections across the mediolateral axis at their terminations.

These axonal reorganisations demonstrate that the position of a ganglion cell within the retina determines not only the ipsilateral or contralateral pathway that is followed at the chiasm, but also the pathway followed within the optic tract. Within the retina, differences must exist between ganglion cells at different retinal loci to govern the different axon behaviours that have been described. It is likely that the specification of axons to take a crossed or an uncrossed course differs from that underlying axon trajectory in the optic trace and may also differ from that specifying the locus of retinotopic termination.

Several candidate molecules for specifying positional information within the retina have been described that show a differential distribution across the retina, but none has yet been shown to have a clear functional role (see Kaprielian and Patterson, 1994). Some of these molecules show a step-like change in distribution across the naso-temporal axis of the retina (McLoon, 1991; Deitcher et al., 1994; Hatini et al., 1994), and these may be linked to naso-temporal differences in cell-cell adhesion that have been identified in the retina (Halfter et al., 1981; Bonhoeffer and Huf, 1985) or with the recognition of cues for the formation of retinotopically organized terminations (Walter et al., 1987; Godement and Bonhoeffer, 1989; Simon and O'Leary, 1992b). Other molecules have a dorso-ventral differential distribution (Trisler et al., 1981; Constantine-Paton et al., 1986; McCaffery et al., 1990; Nornes et al., 1990; Rabbachi et al., 1991) and as such may underlie axonal behavior that segregates dorsal from ventral axons within the tract or at terminal sites. As yet, no marker of uncrossed retinal ganglion cells has been described.

\section{The Normal Development of the Uncrossed Pathway}

Selected stages in the growth of axons, as they navigate the region of the optic chiasm, have been studied in fixed material (Godement et al., 1987a, 1990; Bovolenta and Mason, 1987; Colello and Guillery, 1990; Sretavan, 1990; Baker and Reese, 1993). The recent additional use of time-lapse video microscopy of living axons labeled with fluorescent dyes has added a dynamic view of axon growth through the chiasm (Sretavan and Reichardt, 1993; Godement et al., 1994). Thus, it has been possible to watch labeled uncrossed axons separating from the crossed axons close to the chiasmatic midline. Uncrossed axons coming from dye marked ganglion cells of the ventro-temporal retina of embryonic day 15-17 mice, after the line of decussation has formed, mingle with crossed axons on their way to the chiasm (Godement et al., 1994). As they approach to within $150-200 \mu \mathrm{m}$ of the midline, these uncrossed axons develop claborate, branched growth cones that appear to spread along an unseen midline barrier. These morphological changes occur within a mid-line subpopulation of the radial glia of the diencephalic floor (see next section). The uncrossed axons then make a sharp turn into the optic tract on their own side of the brain (Fig. 2). Such dramatic transitions from simple to more complex forms of growth cone occur at sites in the visual pathways where growing neurites change direction and presumably encounter novel cellular or molecular cues (Bovolenta and Mason, 1987; Harris et al., 1987; Holt, 1989; Wang et al., 1993), and in other pathways in a wide variety of species (references in Godement et al., 1990).

Time-lapse video microscopy has shown a saltatory pattern of growth for all axons along the optic nerve and tract, with axons pausing for minutes between periods of advancing growth (Harris et al., 1987; Sretavan and Reichardt, 1993; Godement et al., 1994). In contrast, during the stages at which the uncrossed axons diverge from the crossed axons, all axons approaching the 


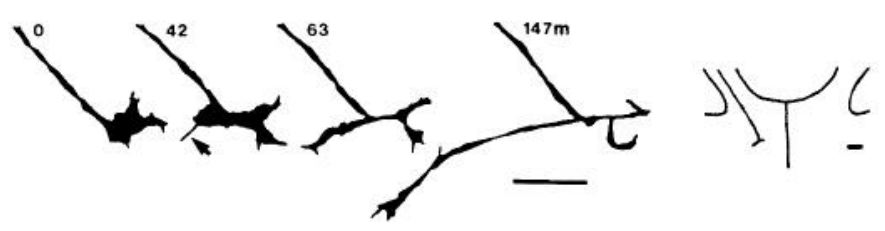

Figure 4. Video images of an axon from the ventro-temporal retina of an E15 mouse, approaching the midline (at $0 \mathrm{~min}$ ), forming complex exploratory outgrowths at 42 and $63 \mathrm{~min}$, including a branch directed back towards the ipsilateral optic tract (arrow). This process expands to form the lead process into the ipsilateral optic tract and thus effects the turn of the growth cone. At $147 \mathrm{~min}$ this branch has extended into the ipsilateral optic tract (from Godement et al., 1994). Long scale bar, $25 \mu \mathrm{m}$; short scale bar, $100 \mu \mathrm{m}$.

midline tend to pause for several hours, advancing and retreating, with no net extension (Godement et al., 1994). The uncrossed axons pause for even longer and go through extreme morphogenetic remodeling. They send out widespread, branched multiple tips for $25-50 \mu \mathrm{m}$, which repeatedly retract back to simple forms. Eventually, a backward pointing filopodium forms and reorients the growth cone into the ipsilateral tract (Fig. 4). It is only at the midline zone that the uncrossed axons from the ventro-temporal retina show behaviors that distinguish them from the crossed axons, although all axons appear to wait at the midline.

At the earliest stages of visual pathway development in mice (E13-14), before the axons from the ventro-temporal part of the retina have developed, axonal outgrowth is more rapid, without the pauses or the extreme remodeling of growth cones in the midline zone (Sretavan and Reichardt, 1993). The axons that remain uncrossed at these early stages come from the early dorso-central ganglion cells (see above, The Retinal Ganglion Cells), which behave differently at the chiasm, either because they cannot respond to the midline cues, or else because the midline cues have not yet developed.

\section{The Cellular Environment at the Optic Chiasm}

At early stages of development of the visual pathways the cellular environment of the chiasm is relatively simple. The retinal axons from each eye come into contact with the axons of the other eye, the radial glia of the diencephalon, and with an early developing population of forebrain neurons described in the second half of this section.

The radial glia have cell bodies in the ependymal lining of the third ventricle and radial processes that form the end feet of the glia limitans. Before retinal axons leave the optic nerve to pass into the chiasm they encounter the radial glia of the diencephalon and tend to move towards the end foot processes of the radial glia.

The turn of the uncrossed axons occurs about $100 \mu \mathrm{m}$ from the midline, after they have passed some distance through the radial glia. This turn occurs within glia that straddle the midline and that have been regarded as a specialized group because at this stage they express epitopes that are not found on radial glia elsewhere in the diencephalon (McKanna, 1993; Marcus et al., 1995; see Fig. 5). In mice, these midline glia are more densely packed than the more lateral glia (Marcus et al., 1995). Finestructural studies have shown that dye-marked uncrossed axons from the ventro-temporal retina relate closely to these processes of the midline cells (Marcus et al., 1995; and see Fig. 6). It has been suggested that the cue mediating the turn of the uncrossed

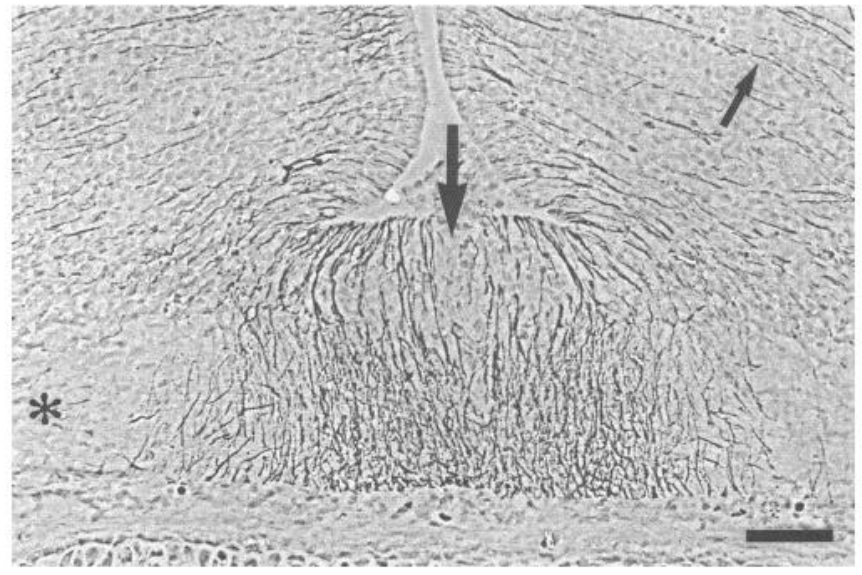

Figure 5. Coronal section from an E16 mouse showing RC2 immunoreactive glia forming a palisade on either side of the chiasmatic midline (arrow). Radial glia are stained in the more lateral diencephalon (smaller arrow), but are lacking in the lateral part of the optic chiasm (*). From Marcus and Mason (1994). Scale bar, $50 \mu \mathrm{m}$.

axons is an inhibitory signal (Godement et al., 1990), preventing advance across the midline, although the nature of the inhibitory molecule is not known.

Evidence for an inhibitory signal in the chiasmatic midline comes from retinal explants cocultured with membranes (Wizenmann et al., 1993) or monolayers (Wang et al., 1992) prepared from cells of the chiasmatic midline. Explants from the ventrotemporal retina of E14-15 mice form shorter and more fasciculated neurites on chiasm cells than do nasal explants. Further, cell aggregations that include radial glia and nonglial cells of the chiasmatic midline from E14 mice are readily traversed by nasal axons, but are avoided by ventro-temporal axons (Wang et al., 1992). A putative inhibitory molecule, chondroitin sulphate, has been demonstrated at the chiasmatic midline, but this is expressed above the axons of the retinofugal pathway, not among them (Lustgarden et al., 1993).

In addition to the glial cells, the chiasmatic midline of many vertebrates, including amphibia, fish, birds, and mammals, contains some early-developing nerve cells of the anterior hypothalamus (Windle, 1935; Windle and Baxter, 1935; Herrick, 1942; Magoun and Ranson, 1942; Taylor, 1991; Easter et al., 1993, 1994; Sretavan et al., 1994). These neurons give rise to the earliest developing axons in the forebrain and contribute to

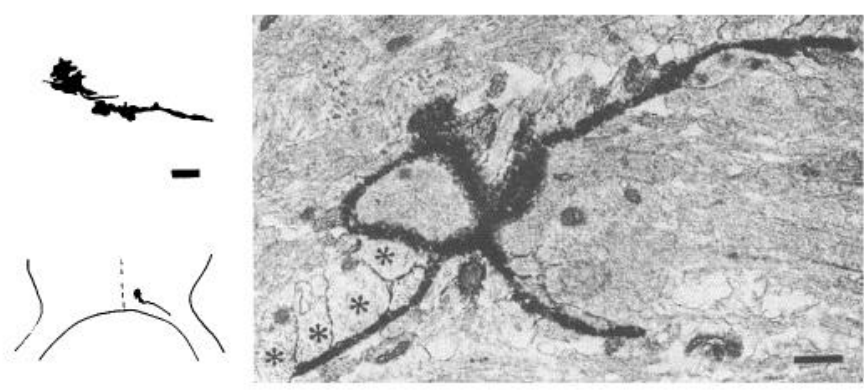

Figure 6. Electron micrograph of a "complex" growth cone, DiI labeled from ventro-temporal retina and photo-oxidized, relating to the radial glial processes (asterisks) of the midline palisade in an E16 mouse. From Marcus and Mason (1994). Scale bars: $0.5 \mu \mathrm{m}$ in electron micrograph and $5 \mu \mathrm{m}$ inset. 
the supraoptic commissures (in fish and frogs these axons have been called the tract of the postoptic commissure; Herrick, 1948). The supraoptic commissures have a wide range of cellular origins in the adult (Tsai, 1925; Tsang, 1940; Magoun and Ranson, 1942; Herrick, 1948), but little is known of the sequence in which the components of the supraoptic commissures develop.

The first retinal axons to enter the ventral diencephalon join the rostral and ventral edge of this commissure, but do not grow among its nonoptic axons (Easter et al., 1994; Sretavan et al., 1994). Possibly an inhibitory signal, such as the high level of tenascin present in the supraoptic commissures of the chick (Perez and Halfter, 1993), or the cell surface protein CD44 (Sretavan et al., 1994), delimits the caudal edge of the optic tract. Retinal axons grow through the diencephalon adjacent to the supraoptic commissures (Easter and Taylor, 1989; Taylor, 1991, Marcus and Mason, 1993; Sretavan et al., 1994), but will still follow a normal course in frogs in the absence of these early axons (Cornell and Holt, 1993; but see Sretavan, 1993).

Thus, although it is probable that the nature of the glial or the extracellular environment at the chiasmatic midline determines the behavior of the advancing growth cones, and although the properties of midline glia in the chiasmatic and other midline regions of the developing neural tube have received considerable attention, the precise properties that determine the pattern of growth of the uncrossed axons are as yet undefined.

\section{Binocular Interactions Determining the Course of the Uncrossed Projection}

The observation of Godement et al. (1987b) that very early, intrauterine removal of one eye in mice produces a severe reduction in the uncrossed component from the other eye has now been confirmed by different methods in mice, ferrets, and rats (Guillery, 1989; Chan and Guillery, 1993; Taylor and Guillery, 1995a). Although this effect was not noted by Sretavan and Reichardt (1993) and seen as only a mild effect by Sretavan and Shatz (1987), this form of binocular interaction is now so well documented that we shall treat it as reflecting a part of normal development.

This reduction of the uncrossed pathway produced by an early, prenatal unilateral eye removal must be clearly distinguished from a quite different developmental change that has been demonstrated in several species by a postnatal removal of one eye. The latter, which produces an increase in the surviving uncrossed component, depends on removal of the crossed retinofugal component after all axons have passed the chiasm, and invasion of the target nuclei is already well advanced. It is thought to be due to the increased access that uncrossed axons have to cells in the target nuclei after the loss of the crossed component. This later, postnatal interaction will not be considered any further here, except to note that, because the prenatal reduction of the uncrossed component and the postnatal increase produce opposite results, the prenatal loss can be best shown at birth, before the postnatal changes can neutralize the prenatal effects.

The reduction of the uncrossed pathway produced by prenatal enucleation depends on the developmental stage at which the operation is done. Early enucleations, done before any axons have reached the chiasm (E11 in mice, E23 in ferrets), produce the most severe reduction, leading to a complete or almost complete failure of the development of the uncrossed component (Fig. 7). Later enucleations produce milder effects, presumably

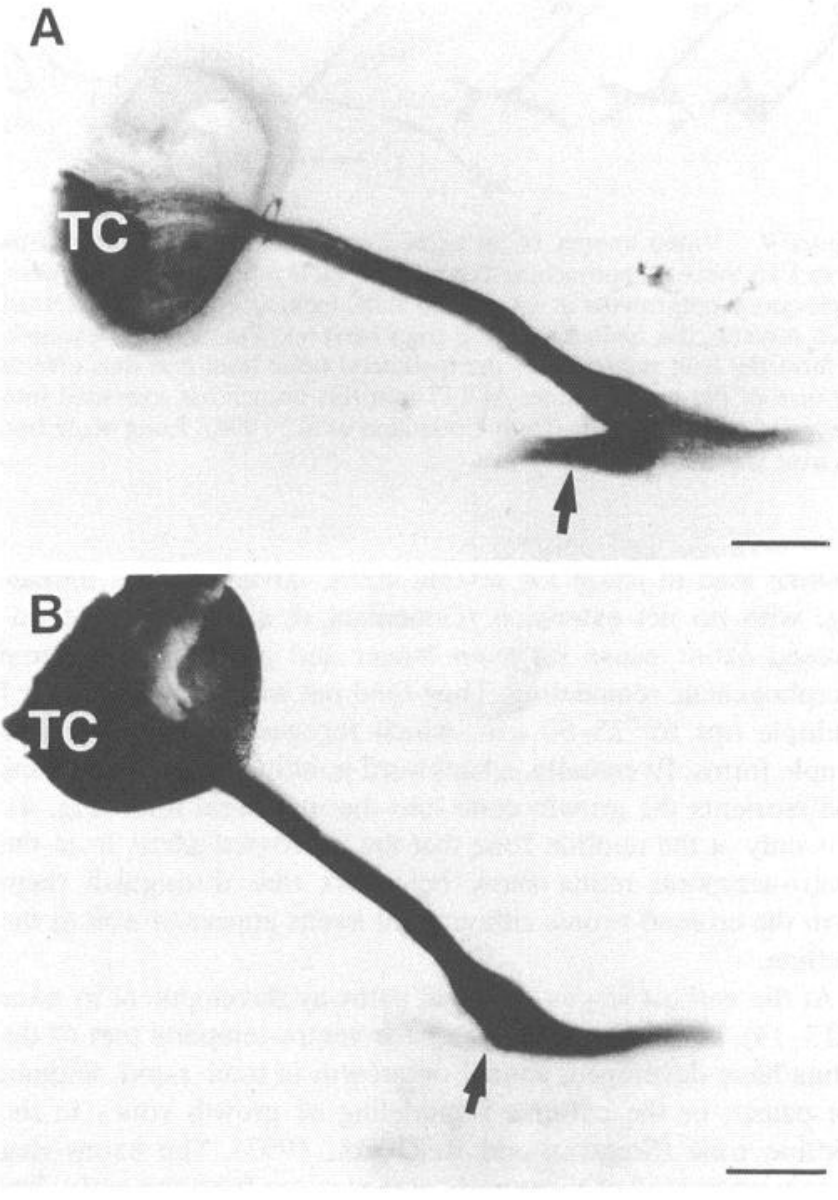

Figure 7. Whole mount preparations of the brains from E30 ferrets in which the temporal crescent (TC) of the right eye has been DiI labeled and photo-oxidized. $A$, The uncrossed projection in the normal E30 ferret (arrow) is prevented from forming ( $B$, arrow) after a monocular enucleation at E23. From Taylor and Guillery (1995a). Scale bars, 500 $\mu \mathrm{m}$.

because axons that have grown past the chiasm at the time of the enucleation are unaffected. These results point to the important role of the crossed component from one eye in guiding the uncrossed axons from the other eye into the optic tract, and show that early uncrossed axons that have already entered the tract appear to be unable to guide later arriving cohorts.

After an enucleation at E13 in mice, growth cones of the uncrossed axons accumulate at the chiasmatic midline by E15 (Godement et al., 1990). Unpublished observations (Godement) of congenitally monocular mice at this stage show a similar accumulation of growth cones, and Godement, Wang, and Mason (unpublished) have made video recordings from monocular enucleate mice in which the uncrossed axons make repeated advances and retractions over many hours, but neither advance across the midline nor turn back to the ipsilateral tract. Studies of ferrets at E30, after an E23-24 monocular enucleation, also show the uncrossed axons from the ventro-temporal retina accumulated at the chiasm (Taylor and Guillery, 1995a).

In contrast to the above, Sretavan and Reichardt (1993) found that after a very early removal of one eye in E11.5 mice, video recording and post mortem backfilling of retinal ganglion cells at E14-16 showed essentially normal chiasmatic development. Some of these reported differences in the effects of early mo- 
nocular enucleations, especially in the observations of living axons, could be due to differences in the developmental stage studied, since one can expect that the uncrossed axons from the early dorso-central component would not respond to any cues at the midline, whereas the later ventro-temporal axons would. Since the switch occurs only shortly before E15, some of the axons not held up at the midline may prove to have been the dorsocentral axons that pass directly into the optic tract on the same side without encountering axons from the other eye. However, other apparently normal uncrossed axons from the ventro-temporal retina described by Sretavan and Reichardt cannot be accounted for in this way, and this discrepancy remains unresolved.

If axons from the ventro-temporal retina that would normally remain uncrossed, fail to follow their normal course into the optic tract after an eye removal, they accumulate at the chiasm; they do not follow other axons, either earlier uncrossed axons that were unimpeded, or axons of the supraoptic commissures, which are present before any of the retinofugal axons. Nor do they turn around and follow the crossed component from their own eye back to the eye from which they came. This last finding might have been expected on the basis of the extent to which the late uncrossed axons appear to depend upon the crossed component for their postchiasmatic course, and from the observation that retinopetal axons are able to grow against the stream towards the eye. The most likely interpretation would be that the axons crossing the mid-line change their surface properties on passing through the midline glia, and become more attractive to the uncrossed axons. This would be comparable to the situation of commissural axons crossing the floor plate of the spinal cord, which express the ncuron-specific protein TAG-1 before and the protein L1 after the crossing (Dodd et al., 1988; Shiga and Oppenheim, 1991). The uncrossed axons may then respond in two stages, first being blocked by the midline structures and then fasciculating with the axons that have switched their surface properties as they crossed the midline.

In summary, the ventro-temporal retinofugal axons that are destined for an uncrossed course travel with those destined for a crossed course from the eye to the chiasm, and in this part of their course the two components are intermingled. They become separated from one another close to midline, where the crossed axons have a relatively free passage through the midline glia, whereas the uncrossed axons are blocked in their path towards the midline. Having been blocked, the uncrossed component then joins the crossed component from the other eye and is dependent upon the latter, particularly on the concurrently growing crossed axons for its further progress into the optic tract.

\section{Abnormal Chiasmatic Pathways}

The uncrossed component of the retinofugal pathway is reduced in all albino mammals studied to date (references in Guillery, 1992). This reduction corresponds to a shift towards the temporal periphery of the line that separates the nasal from the temporal retina.

The abnormality occurs in true albinos, defective in the gene coding for tyrosinase, the enzyme necessary for the synthesis of the retinal pigment, melanin. It is also present in all other mutants in which the melanin of the retinal pigment epithelium shows significant abnormalities. Several different genetic loci have been identified, in mice (LaVail et al., 1978), mink (Sanderson et al., 1974), cals (Creel et al., 1982), and humans (Witkop et al., 1982), mutations at which either reduce the amount of retinal melanin or cause its abnormal cellular distribution. All such mutants show a reduced uncrossed pathway. Neural-crestderived melanin appears to play no part in relation to this abnormality (Sanderson et al., 1974; Witkop et al., 1982). The mechanism that produces the abnormality is not understood, although it is reasonable to conclude that the tyrosinase does not participate directly in producing the abnormal pathway and to expect that the mechanism concerned is clusely linked to the synthesis or breakdown of retinal melanin.

Since the crossed and the uncrossed axons are mingled on the way to the chiasm, there are a limited number of mechanisms that could produce this shift in the retinal line of decussation. In view of its close relation to retinal melanin, the production of the abnormality is most likely to be dependent upon a retinal rather than a chiasmatic deficiency. Comparisons of normal and albino chiasms and of axonal growth from normal and albino ganglion cells in vitro, support this conclusion (Marcus and Mason, 1994, and unpublished observations).

The similarity of the reduced ipsilateral termination in albino mice and ferrets to that found after early removal of one eye suggested that both reductions might involve similar mechanisms, a view reinforced by the failure of early enucleations in albino ferrets to produce any reduction of the uncrossed termination to the lateral geniculate nuclcus (Guillcry, 1989). However, recent, more detailed studies of retinal ganglion cells giving rise to the uncrossed pathway have shown that the albino effect and the enucleation effect are fundamentally different (Chan and Guillery, 1993). Whereas albinism shifts the line of decussation (the line that defines the border of the ventro-temporal crescent) towards the temporal periphery, enucleation reduces the number of ipsilaterally projecting ganglion cells, without changing the position of the line of decussation. Further, the number of ipsilaterally projecting ganglion cells is also reduced by an early enucleation in albinos.

An abnormality of the optic chiasm, found in two children (Apkarian et al., 1994) and in a breed of Belgian sheepdog (Williams et al., 1994), has been described recently, in which no retinofugal axons cross the midline. All of the axons in the optic nerve pass to the brain without crossing. It is not clear as yet whether in this abnormality there is a complete absence of crossing axons in the region of the chiasm, or whether the supraoptic commissures remain normally crossed.

A major question arising out of both types of abnormality, reduced as well as increased crossing, concerns the way in which the terminals of the abnormally routed axons are distributed in the brain and the way in which this distribution alters the normal functioning of the visual centcrs. These questions are beyond the scope of this article (but see Hubel and Wiesel, 1971; Kaas and Guillery, 1973; Shatz, 1977; Shatz and LeVay, 1979). They are mentioned here because they raise another question, namely, what is the normal optic chiasm for?

\section{The Optic Chiasm of Marsupials}

An early observation by Bodian (1936), made in the North American opossum, and several more recent studies of other marsupials (Harman and Jeffery, 1992; Jeffery and Harman, 1992; Guillery and Taylor, 1993; Taylor and Guillery, 1994) have shown that in all marsupials studied to date, the uncrossed retinofugal pathway separates from the crossed pathway within the prechiasmatic nerve, rather than near the midline within the chiasm itself, as in eutherian mammals. In the mid-portion of the nerve, the crossed and the uncrossed components are not 


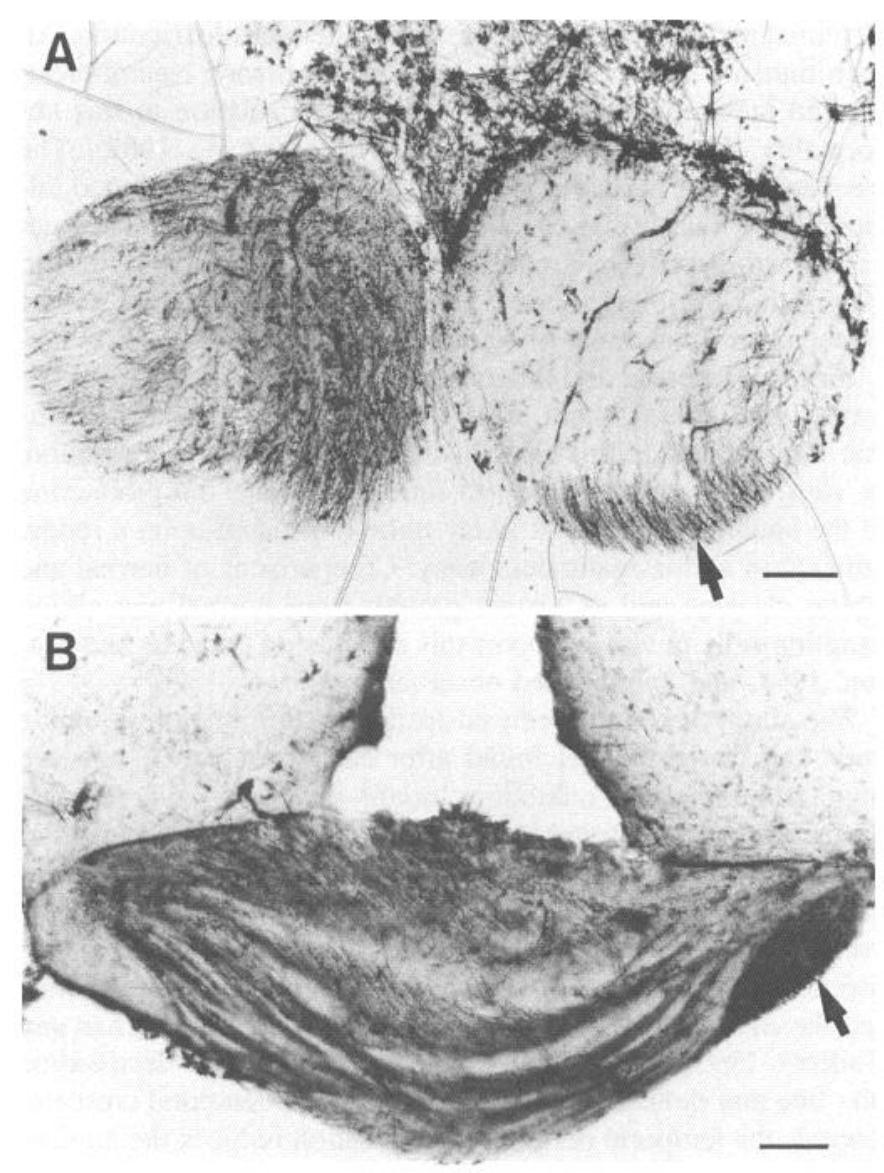

Figure 8. Coronal sections through the optic nerves $(A)$ and the optic chiasm $(B)$ of an adult Monodelphis, in which HRP had been injected into the right optic tract. The uncrossed axons (arrow in $A$ ) are segregated within the optic nerve and pass as a discrete bundle in the lateral part of the optic chiasm (arrow in $B$ ). In the optic chiasm, the crossing axons form a series of interdigitating bundles. $A$, from Taylor and Guillery (1994); $B$, from Guillery and Taylor, (1993). Scale bars, $100 \mu \mathrm{m}$.

restricted to different parts of the cross-section of the nerve, but are mingled, as in eutherians. Then, as the axons approach the chiasm in the marsupials, the uncrossed component separates from the crossed component, passing ventrally through the crossed component, and collecting as a separate bundle in the ventro-lateral part of the prechiasmatic nerve (Fig. $8 \mathrm{~A}$ ).

The crossed axons continue their course as separate and rather distinct bundles across the midline, and at the midline there is an interdigitation of the crossing bundles that gives the optic chiasm a different structure from that seen in eutherians (Fig. $8 B)$. In this respect these marsupial chiasms are very like the avian or reptilian chiasm, which also has rather large interdigitating bundles at the midline (Polyak, 1957). The intimate mingling of the crossing axons that is seen in frogs and eutherian mammals suggests a distinct developmental sequence that as yet remains to be defined.

In the early development of the optic chiasm of the marsupial Monodelphis domestica, one sees some of the same features that we have described above for eutherians. There is an early uncrossed projection from the dorso-central retina. There is also a later clear separation in the retina of nasal (crossed) from temporal (uncrossed) ganglion cells (Taylor and Guillery, 1994). As in eutherians, the interfascicular glia of the optic nerve are re- placed by radial glia of the diencephalon, and this transition occurs within the prechiasmatic part of the nerve. However, at this border, one sees the segregation of uncrossed from the crossed axons, rather than an age-related reordering. The axons of the uncrossed component change direction, passing towards the pia at the ventro-lateral surface of the nerve. Ultrastructural observations show that in this region the growth cones of the uncrossed axons are associated with the radial glial processes (Taylor and Guillery, 1994). Once these uncrossed axons have reached the sub-pial endfeet, they accumulate as a well-defined bundle and make a second perpendicular turn across the face of the nerve to enter the ipsilateral optic tract. Within the optic tract itself, the crossed and the uncrossed axons appear to be in an age-related order (Cavalcante et al., 1993), but so far the region where this order appears has not been defined, and we do not know how the glial environment relates to this further change in axonal order.

The relationships we have described show that the glial border zone between interfascicular and radial glia, a structural landmark that appears to have the same developmental origins in marsupials and eutherians, plays a completely different role in the guidance of axons in the two mammalian orders. In eutherians, the axons begin to take on an age related order as they enter the radial glial zone, but the uncrossed component does not separate from the crossed component until the axons are much nearer the midline and mingled with crossing axons from the other eye. In Monodelphis, the uncrossed axons separate when they first encounter the radial glia, and the place at which the age related order is established remains to be defined.

The structure of the chiasm in marsupials was earlier related to another of their characteristic features. Whereas, as we have seen, a very early monocular enucleation produces a reduction in the uncrossed pathway in eutherians, there is no evidence for any such effect in marsupials (Mendez-Otero et al., 1986; Coleman and Beazley, 1989). However, these studies were all based upon studies of the uncrossed component in adults, and, as pointed out earlier, since an early enucleation has the opposite effect to one done after the chiasm has formed, the later developmental changes could have neutralized the effects of these early enucleations.

Recent studies with relatively short postoperative survival times in Monodelphis demonstrate that this is not the explanation of the difference. The early enucleation does not reduce the size of the uncrossed component (Taylor and Guillery, 1995b). The uncrossed axons, like the early dorso-central uncrossed axons of eutherians, are not dependent upon the crossed component from the other eye, and since the two do not encounter each other until well after the commitment to a crossed or an uncrossed pathway has been made, this lack of any interaction is to be expected.

One other problem about the marsupial chiasm that remains unresolved concerns the albino abnormality. At present, we do not know whether there is a reduction of the uncrossed component in albino marsupials. In so far as one can regard the albino abnormality as due to retinal factors, one might expect marsupials to show the same abnormalities as eutherians. It is only if a chiasmatic factor plays a significant role in the production of the abnormality that one can anticipate a difference between eutherians and marsupials in the expression of the abnormality. 


\section{Summary and Conclusions}

The mammalian optic chiasm is widely and properly regarded as a region where axons from the temporal retina take an uncrossed course and separate from axons arising in the nasal retina that take a crossed course. However, this is but a rough approximation of the adult situation, and developmental studies must take account of several distinctive stages and axon rearrangements that characterize the region of the chiasm. At the early and late stages of development of nonprimate species the axons do not segregate in accordance with a strict naso-temporal rule at all, and their behavior at the chiasm is not relevant to the formation of the naso-temporal division.

As the axons pass trom the eye to the chiasm they tend to lose their retinotopic order, to gain a chronotopic order, and then, in the region of the chiasm, to regain some aspects of the retinotopic order before reaching their terminal sites. Molecular or cellular cues that allow the several distinct organizational steps to occur must be expected in the retina, on the axons themselves, and also along the pathway of the axons, prechiasmatically and at the chiasm. Some of these cues will be associated with local nerve cells, some with specialized glial elements and some with the retinofugal axuns themselves. Several candidate molecules have been identified in the retina and along the path of the axons, but to date no clearly defined role in the specific events of the pathway determination have been identified.

The sequence of developmental processes that characterizes the formation of the optic chiasm provides an interesting and useful challenge to experimentalists, because the advancing axons can now be observed in vitro and in the living brain. The pattern of growth changes as development proceeds, it shows distinctive properties in different species and in their genetic mutants, and it can be readily modified by simple experimental procedures. These all provide opportunities for investigating the function of proposed molecular cues that act in the development of the chiasm.

\section{References}

Apkarian P, Bour L, Barth PG (1994) A unique achiasmatic anomaly detected in non-albinos with misrouted retinofugal projections. Eur $\mathbf{J}$ Neurosei 6:501-507.

Baker GE, Collello RJ (1994) The origin and course of retinofugal axons during normal development of the ferret. Soc Neurosci Abstr 20:449.9.

Baker GE, Jeffery G (1989) Distribution of uncrossed axons along the course of the optic nerve and chiasm in rodents. J Comp Neurol 289: $455-461$.

Baker GE, Reese BE (1993) Chiasmatic course of temporal retinal axons in the developing ferret. J Comp Neurol 330:95-104.

Bernhardt R (1994) Ipsi- and contralateral commissural growth cones react differentially to the cellular environment of the ventral zebrafish spinal cord. J Comp Neurol 350:122-132.

Bernhardt R, Easter SS Jr (1986) Map of retinal position onto the cross section of the optic pathway of goldfish. J Comp Neurol 254:493 510.

Bodian D (1936) An experimental study of the optic tracts and retinal projection of the Virginia opossum. J Comp Neurol 66:113-144.

Bonhoeffer F, Huf J (1985) Position dependent properties of retinal axons and their growth cones. Nature 315:409-410.

Bovolenta P, Mason CA (1987) Growth cone morphology varies with position in the developing mouse visual pathway from retina to first targets. J Neurosci 7:1447-1460.

Cavalcante LA, Allodi S, Reese BE (1993) Fibre order in the opossum's optic tract. Anat Embryol (Berl) 186:589-600.

Chalupa LM, Lia B (1991) The nasotemporal division of retinal ganglion cells with crossed and uncrossed projections in the fetal rhesus monkey. J Neurosci 11:191-202.

Chan SO, Guillery RW (1993) Developmental changes produced in the retinofugal pathways of rats and ferrets after early monocular enucleation: the effects of age and the difference between albino and normal animals. J Neurosci 13:5277-5293.

Chan SO, Guillery RW (1994) Changes in fiber order in the optic nerve and tract of rat embryos. J Comp Neurol 344:20-32.

Chan SO, Baker GE, Guillery RW (1993) Differential action of the albino mutation on two components of the rat's retinofugal pathway. J Comp Neurol 308:234-456.

Colello RJ, Guillery RW (1990) The early development of retinal ganglion cells with uncrossed axons in the mouse: retinal position and axonal course. Development 108:515-523.

Colello RJ, Guillery RW (1992) Observations on the early development of the optic nerve and tract in the mousc. J Comp Ncurol 317: 357-378.

Coleman LA, Beazley LD (1989) Retinal ganglion cell number is unchanged in the remaining eye following early unilateral eye removal in the wallaby Setonix brachyurus, quokka. Dev Brain Res 48:293307

Constantine-Paton M, Blum AS, Mendez-Otero R, Barnstable CJ (1986) A cell surface molecule distributed in a dorso-ventral gradient in the perinatal rat retina. Nature 324:459-462.

Cornell E, Holt CE (1993) Precocious pathfinding: retinal axons can navigate in an axonless brain. Neuron 9:1001-1011.

Creel D, Hendrickson AE, Leventhal AG (1982) Retinal projections in tyrosinase negative albino cats. J Neurosci 2:907-911.

Cucchiaro J, Guillery RW (1984) The development of the retinogeniculate palhways in nomal and albino ferrets. Proc R Soc Lond [Biol] 223:141-164.

Deitcher DL, Fekete DM, Cepko CL (1994) Asymmetric expression of a novel homeobox gene in vertebrate sensory organs. J Neurosci $14: 486-$.

Dodd J, Morton SB, Karagogeos D, Yamamoto M, Jessell TM (1988) Spatial segregation of axonal glycoprotein expression on subsets of embryonic spinal neurons. Neuron 1:105-116.

Dräger UC (1981) Birth dates of retinal ganglion cells giving rise to the crossed and uncrossed optic projections in the mouse. Proc R Soc Lond [Biol] 224:57-77.

Easter SS Jr, Taylor JSII (1989) The development of the Xenopus retinofugal pathway: optic fibres join a pre-existing tract. Development 107:553-573.

Easter SS Jr, Rusoff AC, Kish PE (1981) The growth and organisation of the optic nerve and tract in juvenile and adult goldfish. J Neurosci 1:793-811.

Easter SS, Ross LS, Frankfurter A (1993) Initial tract formation in the mouse brain. J Neurosci 13:285-299.

Easter SS, Burrill J, Marcus RC, Ross LS, Taylor JSH, Wilson SW (1994) Initial tract formation in the vertebrate brain. Prog Brain Res 102:79-93.

Fawcett JW, Gaze RM (1982) The retinotectal fibre pathways from normal and compound eyes in Xenopus. J Embryol Exp Morphol 72: $19-37$.

Fawcett JW, Taylor JSH, Gaze RM, Grant P, Hirst E (1984) Fibre order in the normal Xenopus optic tract, near the chiasma. J Embryol Exp Morphol 83:1-14.

Fujisawa H, Watanabe K, Tani N, Ibata Y (1981) Retinotopic analysis of fiber pathways in amphibians. I. The adult newt Cynops pyrrhogaster. Brain Res 206:9-20.

Gaze RM (1970) The formation of nerve connections. London: Academic.

Gaze RM, Grant P (1978) The diencephalic course of regenerating retinotectal fibres in Xenopus tadpoles. J Embryol Exp Morphol 44: 201-216.

Godement P, Bonhoeffer $\Gamma$ (1989) Cross-species recognition of tectal cues by retinal fibres in vitro. Development 106:313-320.

Godement P, Mason CA (1993) Guidance of retina fibres in the optic chiasm. Persp Dev Biol 4:217-225.

Godement P, Salaün J, Métin C (1987a) Fate of uncrossed retinal projections following early or late prenatal monocular enucleation in the mouse. J Comp Neurol 255:97-109.

Godement P, Vanselow J, Thanos S, Bonhoeffer F (1987b) A study of the developing visual systems with a new method of staining neurones and their processes in fixed tissue. Development 101:697-713.

Godement P, Salaiun J, Mason CA (1990) Retinal axon pathfinding in the optic chiasm: divergence of crossed and uncrossed fibers. Neuron $5: 173-186$ 
Godement P, Wang LC, Mason CA (1994) Retinal axon divergence in the optic chiasm: dynamics of growth cone behaviour at the midline. J Neurosci 14:7024-7039.

Guillery RW (1989) Early monocular enucleation in foetal ferrets produce a decrease of uncrossed and an increase of crossed retinofugal components: a possible model for the albino abnormality. J Anat 164: 73-84.

Guillery RW (1992) Rules that govern the development of the pathways from the eye to the optic tract in mammals. In: Development of the visual system (Lam DM, Shatz CS, eds). Cambridge, MA: MIT Press.

Guillery RW, Taylor JSH (1993) Different rates of axonal degeneration in the crossed and uncrossed retinofugal pathways of Monodelphis domestica. J Neurocytol 22:707-716.

Guillery RW, Walsh C (1987) Changing glial organisation relates to changing fibre order in the developing optic nerve of ferrets. J Comp Neurol 265:203-217.

Halfter W, Claviez M, Schwarz U (1981) Preferential adhesion of tectal membranes to anterior embryonic chick retina neurites. Nature 292: $67-70$.

Harman AM, Jeffery G (1992) The distinctive pattern of organisation in the retinofugal pathway of a marsupial. I. Retina and optic nerve. J Comp Neurol 325:47-56.

Harris WA, Holt CE, Bonhoeffer F (1987) Retinal axons with and without their somata, growing to and arborising in the tectum of Xenopus embryos: a time-lapse video study of single fibre in vivo. Development 101:123-133.

Hatini V, Toa W, Lai E (1994) Expression of winged helix genes BF-1 and $\mathrm{BF}-2$ define adjacent domains within the developing forebrain and retina. J Neurobiol 25:1293-1309.

Herrick CJ (1942) Optic and post-optic systems in the brain of Amblystoma tigrinum. J Comp Neurol 77:191-353.

Herrick CJ (1948) The brain of the tiger salamander. Chicago: University of Chicago.

Holt CE (1990) A single cell analysis of early retinal ganglion cell differentiation in Xenopus: from soma to axon tip. J Neurosei 9:3123-3145.

Horton JC, Greenwood MM, Hubel DH (1979) Non-retinotopic arrangement of fibres in the cat optic nerve. Nature 282:720-722.

Hubel D, Wiesel T (1971) Aberrant visual projections in the Siamese cat. I Physiol (I ond) 218:33-6?

Jeffery G, Harman AM (1992) The distinctive pattern of organisation in the retinofugal pathway of a marsupial. II. Optic chiasm. J Comp Neurol 325:57-67.

Johns P (1977) Growth of the goldfish eye. III. Source of the new retinal cells. J Comp Neurol 176:343-358.

Kaas JH, Guillery RW (1973) The transfer of abnormal visual field representations from the dorsal lateral geniculate nucleus to the visual cortex in Siamese cats. Brain Res 59:61-95.

Kaprielian Z, Patterson P (1994) The molecular basis of retinotectal topography. Bioessays 16:1-11.

Klämbt C, Jacobs RJ, Goodman CS (1991) The midline of the Drosophila CNS: a model for the genetic analysis of cell fate, cell migrations and growth cone guidance. Cell 64:801-815.

LaVail JH, Nixon RA, Sidman RL (1978) Genetic control of retinal ganglion cell projections. J Comp Neurol 182:399-422.

Levine RL (1989) Organisation of astrocytes in the visual pathways of the goldfish: an immunohistochemical study. J Comp Neurol 285: $3231-245$

Lia B (1992) Retinal decussation patterns in the rhesus monkey embryo. Soc Neurosci Abstr 18:1133.

Lustgarden JH, Marcus RC, Wang L-C, Mason CA (1993) Chondroitin sulfate is localized at the midline during retinal axon divergence in the mouse optic chiasm. Soc Neurosci Abstr 19:1418.

Maggs A, Scholes J (1986) Glial domains and nerve fibre patterns in the fish retinotectal pathway. I Neurosci 6:424-438.

Magoun HW, Ranson M (1942) The supraoptic decussation in the cat and monkey. J Comp Neurol 76:435-460.

Marcus RC, Mason CA (1993) Early retinal axon growth in the mousc ventral diencephalon. Soc Neurosci Abstr 19:1418.

Marcus RC, Mason CA (1994) Development of crossed and uncrossed visual pathways in pigmented and albino mice. Soc Neurosci Abstr 20:1085.

Marcus RC, Blazeski R, Godement P, Mason CA (1995) Retinal axon divergence within the optic chiasm: uncrossed axons diverge from crossed fibers within a midline glial specialization. $\mathbf{J}$ Neurosci, in press.

McCaffery P, Neve RL, Drager UC (1990) A dorso-ventral asymmetry in the embryonic retina defined by a protein conformation. Proc Natl Acad Sci USA 87:8570-8574.

McKanna JA (1993) Optic chiasm and infundibular decussation sites in the developing rat diencephalon are defined by glial raphes expressing p35 (lipocotin I, annexin I). Dev Dynamics 195:76-86.

McLoon SC (1991) A monoclonal antibody that distinguishes between temporal and nasal retinal axons. J Neurosci 11:1470-1477.

Mendez-Otero R, Rocha-Miranda CE, Carvalho-Dias E (1986) Effects of monocular enucleation at different stages of development on the uncrossed retinocollicular projection in the opossum. Dev Brain Res 27:101-108.

Naito J (1986) Course of retinogeniculate projection fibers in the cat optic nerve. J Comp Neurol 251:376-387.

Naito J (1989) Retinogeniculate projection fibres in the monkey optic nerve: a demonstration of the fibre pathways by retrograde axonal transport of WGA-HKP. J Comp Neurol 284:174-186.

Nornes JO, Dressler GR, Knapik EW, Deutsch U, Gruss P (1990) Spatially and temporally restricted expression of Pax2 during murine neurogenesis. Development 109:797-809.

Perez RG, Halfter W (1993) Tenascin in the developing chick visual system: distribution and potential role as a modulator of retinal growth. Dev Biol 156:278-292.

Polyak S (1957) The vertebrate visual system. Chicago: University of Chicago.

Rabbachi SA, Neve RL, Drager UC (1991) A positional marker for the dorsal embryonic retina is homologous to the high-affinity laminin receptor. Development 109:521-531.

Reese BE, Baker GE (1990) The course of fibre diameter classes through the chiasmatic region in the ferret. Eur J Neurosci 2:34-49.

Reese BE, Baker GE (1992) Changes in fiber organization within the chiasmatic region of mammals. Vis Neurosci 9:527-533.

Reese BE, Baker GE (1993) The re-establishment of the representation of the dorso-ventral retinal axis in the chiasmatic region of the ferret. Vis Neurosci 10:957-968

Reese BE, Guillery RW, Mallarino C (1992) Time of gantglion cell genesis in relation to the chiasmatic pathway choice of retinofugal axons. J Comp Neurol 324:336-342.

Reese BE, Maynard TM, Hocking DR (1994) Glial domains and axonal reordering in the chiasmatic region of the developing ferret. $J$ Comp Neurol 349:303-324.

Reh TA, Pitts E, Constantine-Paton M (1983) The organisation of fibres in normal and tectum-less Rana pipiens. J Comp Neurol 218: 282-296.

Sanderson KJ, Guillery RW, Shackelford RM (1974) Congenitally abnormal visual pathways in the mink (Mustela vison) with reduced retinal pigment. J Comp Neurol 154:225-248.

Scalia F, Fite K (1974) A retinotopic analysis of the central connections of the optic nerve of the frog. J Comp Neurol 158:455-478.

Scholes JH (1979) Nerve fibre topography in the retinal projection to the tectum. Nature 278:620-624.

Seeger M, Tear M, Ferrees-Marco D, Goodman CS (1992) Mutations affecting growth cone guidance in Drosophila: genes necessary for guidance toward and away from the mid-line. Neuron 10:409-426.

Shatz CJ (1977) Anatomy of interhemispheric connections in the visual system of Boston Siamese and ordinary cats. J Comp Neurol 173: $497-518$.

Shatz CJ, LeVay S (1979) Siamese cat: altered connections of visual cortex. Science 204:328-330.

Shepherd IS, Taylor JSH (1995) The early development of efferent projections from the chick tectum. J Comp Neurol 354:501-510.

Shiga T, Oppenheim RW (1991) Immunolocalisation studies of putative guidance molecules used by axons and growth cones of intersegmental interneurons in the chick embryo spinal cord. J Comp Neurol 310:234-252.

Sidman RL (1961) Histogenesis of the mouse retina studied with thymidine- $\mathrm{H}^{3}$. In: The structure of the eye (Smelser GK, ed). New York: Academic.

Silver J (1984) Studies on the factors that govern directionality of axonal growth in the embryonic optic nerve and at the chiasm of mice. J Comp Neurol 223:238-251.

Simon DK, O'Leary DDM (1992a) Influence of the position along the 
medial-lateral axis of the superior colliculus on the topographic targeting and survival of retinal axons. Dev Brain Res 69:167-172.

Simlon DK, O'Leary DDM (1992b) Responses of retinal axons in vivo and in vitro to position encoding molecules in the embryonic superior colliculus. Neuron 9:977-989.

Sretavan DW (1990) Specific routing of retinal ganglion cell axons at the mammalian optic chiasm during embryonic development. J Neurosci 10:1955-2007.

Sretavan DW (1993) Pathfinding at the mammalian optic chiasm. Curr Opin Neurobiol 3:45-52.

Sretavan DW, Reichardt LF (1993) Time lapse viden analysis of retinal ganglion cell axon pathfinding at the optic chiasm: growth cone guidance using intrinsic chiasm cues. Neuron 10:761-777.

Sretavan DW, Shatz CJ (1986) Prenatal development of cat retinogeniculate axon arbors in the absence of binocular interactions. J Neurosci 6:990-1003.

Sretavan DW, Feng L, Pure E, Reichardt LF (1994) Embr yonic neurons of the developing optic chiasm express L1 and CD44, cell surface molecules with opposing effects on retinal axon growth. Neuron 12: 957-975.

Stone J, Fukuda Y (1974) The naso-temporal division of the cat's retina re-examined in terms of X-, Y-, and W-cells. J Comp Neurol 155: $722-747$.

Stone J, Leicester J, Sherman SM (1973) The naso-temporal division of the monkey's retina. J Comp Neurol 150:333-348.

Straznicky C, Gaze RM (1971) The growth of the retina in Xenopus laevis: an autoradiographic study. J Embryol. Exp Morphol 26:6779.

Taylor JSH (1987) Fibre organisation and reorganisation in the retinotectal projection of Xenopus. Development 99:393-410.

Taylor JSII (1991) The early development of the frog retinotectal projection. Development [Suppl] 2:95-104.

Taylor JSH, Guillery RW (1994) The development of the uncrossed retinofugal projection in Monodelphis domestica. J Comp Neurol 350:109-121.

Taylor JSH, Guillery RW (1995a) The effect of a very early monocular enucleation upon the development of the uncrossed retinofugal pathway in ferrets. J Comp Neurol 357:1-10.

Taylor JSH, Guillery RW (1995b) Does early monocular enucleation in a marsupial affect the surviving uncrossed retinofugal pathway? J Anat 186:335-342

Thompson ID, Morgan JE (1993) The development of retinal ganglion cell decussation patterns in postnatal pigmented and albino ferrets. Eur J Neurosci 5:341-356.

Torrealba F, Guillery RW, Eysel U, Polley LII, Mason CA (1982) Studies of retinal representations within the cat's optic tract. J Comp Neurol 211:377-396.

Trisler GD, Schneider MD, Nirenberg M (1981) A topographic gra- dient of molecules in the retina can be used to identify neuron position. Proc Natl Acad Sci USA 78:2145-2149.

Tsai C (1925) The optic tracts and centres in the opossum. J Comp Neurol 39:173-216.

Tsang Y-C (1940) Supra- and post-optic commissures in the brain of the rat. J Comp Neurol 72:535-566.

Udin SB, Fawcett JW (1988) Formation of topographic maps. Annu Rev Neurosci 11:289-328.

Vitek DJ, Sehall JD, Leventhal AG (1985) Morphology, central projections and dendritic field orientation of retinal ganglion cells in the ferret. I Comp Nenrol 241:1-11.

Walsh C, Guillery RW (1985) Age-related fiber order in the optic tract of the ferret. J Neurosci 5:3061-3070.

Walsh C, Polley EH, Hickey TL, Guillery RW (1983) Generation of cat retinal ganglion cells in relation to central pathways. Nature 302 : 611-614.

Walter J, Henke-Fahle S, Bonhweffer F (1987) Avoidance of posterior tectal membranes by temporal retinal axons. Development 101:909.

Wang L-C, Godement P, Mason CA (1992) Cells of the optic chiasm midline inhibit uncrossed retinal tiber outgrowth in vitro. Soc Neurosci Abstr 18:222.

Wang L-C, Godement P, Mason CA (1993) Growth cone behaviour is behaviour and position-specific. Soc Neurosei Abstr 19:620.

Williams RW, Bastiani MJ, Lia B, Chalupa LM (1986) Growth cones, dying axons, and developmental fluctuations in the fiber population of the cat's optic nerve. J Comp Neurol 246:32-69.

Williams RW, Hogan D, Garraghty PE (1994) Target recognition and visual maps in the thalamus of achiasmatic dogs. Nature $367: 637$ 639.

Wilson MA, Taylor JSH, Gaze RM (1988) A developmental and ultrastructural study of the optic chiasma in Xenopus. Development 102: $537-553$.

Windel WF (1935) Neurofibrillar development of the cat embryo: extent of development in the telencephalon and diencephalon up to 15 mm. J Comp Neurol 63:139-172.

Windel WF, Baxter RE (1935) The first neurofibrillar development in albino rat embryos. J Comp Neurol 63:173-188.

Witkop C, Jay B, Creel D, Guillery RW (1982) Optic and otic neurologic abnormalities in oculocutaneous and ocular albinism. Proc Natl Acad Sci USA 82:3906-3910.

Wizenmann A, Thanos S, Boxberg YV, Bonhoeffer F (1993) Differential reactions of crossing and non-crossing rat retinal axons on cell membrane preparations from the chiasm midline: an in vitro study. Development 117:725-735.

Yagimuna HS, Homma S, Kunzi R, Oppenheim RW (1991) Pathfinding by growth cones of commissural interneurons in the chick embryo spinal cord: a light and electronmicroscope study. J Comp Neurol 304:78-102. 